\title{
TEMAS MÍTICOS EN DOS CUENTOS DE RUBÉN DARÍO
}

Marcos RuIz SÁNCHEZ

Universidad de Murcia

\section{RESUMEN}

La mitología está presente en distintos niveles dentro de la obra de Rubén Darío. En algunos casos aparece explícitamente dentro de la anécdota del relato o del poema. En otros cabe hablar, en cambio, de mitología subyacente, cuando los temas míticos se han convertido en elementos arquetípicos que el autor hereda juntamente con los motivos de la tradición literaria. En este sentido se analizan dos relatos de Azul... La ninfa y El rubí. En el primero están presentes explícitamente una serie de personajes y de motivos míticos. En el segundo la metamorfosis del rubí, de evidente raíz alquímica, tiene un paralelo en el tema de la metamorfosis de la rosa, ligado en la mitología al nacimiento de Venus, motivo que había sido objeto, por otra parte, de una larga reelaboración literaria y que el propio autor utiliza con frecuencia en sus obras.

LA CONTEMPLACIÓN: EL CENTAURO, LA NINFA Y EL SÁTIRO

El centauro aparece brevemente en uno de los cuentos de $A z u l . .$, La ninfa (cuento parisiense). Los personajes del relato discuten sobre obras de arte, lo que da pie a que la protagonista, Lesbia, afirme que desearía que se animaran 
las figuras de sátiros y centauros. Sigue una discusión sobre la existencia real de tales personajes mitológicos, que da lugar a la disertación de un personaje, un sabio, futuro miembro del Instituto, quien aduce testimonios que evocan el ambiente del bajo imperio romano y de la Edad Media. Uno de los relatos se refiere a San Antonio:

San Antonio Abad, de edad de noventa años, fue en busca del viejo ermitaño Pablo, que vivía en una cueva (...). Iba el santo por el vermo, apoyado en su báculo, sin saber dónde encontrar a quien buscaba. A mucho andar, ¿sabéis quién le dio las señas del camino que debía seguir? Un centauro: "medio hombre y medio caballo», dice el autor. Hablaba como enojado; huyó tan velozmente, que pronto le perdió de vista el santo; así iba galopando el monstruo, cabellos al aire $y$ vientre en tierra.

En ese mismo viaje, San Antonio vio un sátiro, "hombrecillo de extraña figura, estaba junto a un arroyuelo, tenía las narices corvas. frente áspera y arrugada, y la última parte de su contrahecho cuerpo remataba con pies de cabra».

La presencia en el cuento de este tipo de leyendas, que Darío recoge casi al pie de la letra de sus fuentes, resulta desde el punto de vista literario sumamente interesante ${ }^{1}$. El propio Darío utilizará la misma leyenda en otro de sus cuentos, Palimpsesto, denominado también El sátiro y el centauro ${ }^{2}$, y $\mathrm{G}$. Valencia escribirá sobre el tema del encuentro entre S. Antonio y el centauro, un extenso poema que recuerda mucho formalmente el Coloquio de los centauros ${ }^{3}$. La figura de S. Antonio evocaba, por otra parte, inevitablemente las famosas Tentaciones de San Antonio de Flaubert ${ }^{4}$.

' Cf. para las fuentes de este pasaje, así como para las fuentes francesas en las que Darío basa el tono del cuento, ARTuRo Marasso (1934), Rubén Darió y su creación poética, La Plata, pp. 317 320. M. T. Maiorana (1958), «El coloquio de los centauros de Rubén Darío», Boletín de la Academia Argentina de las Letras, 23, pp. $185-263$ [pp. 247 y ss.], R. LlOPESA, (1992), «Las fuentes literarias de La ninfa", Revista de Literatura, 107, pp. 247-255, y J. E. AREllano (1993), Azul... de Rubén Dario. Nuevas perspectivas, 1993, S. Mary Press, EE.UU. La fuente más remota es el pasaje de S. Jerónimo al que hacemos referencia más adelante, a través de la traducción de Fray Jerónimo Cavalca.

${ }^{2}$ En su semblanza de Paul Verlaine Dario recuerda este tipo de historias: Mas ¿habéis leido unas bellas historias renovadas por Anatole France de viejas narraciones hagiográficas, en las cuales hay sátiros que adoran a Dios, y creen en su cielo y en sus santos. llegando en ocasiones hasta a ser santos sátiros?

"El poema de G. Valencia (1955, Obras poéticas completas, Madrid, p. 140) lleva una larga introducción que recoge el pasaje de la Vida de Pablo el eremita de S. Jerónimo, que es el origen de esta historia.

${ }^{4}$ Cf. sobre el uso de la intertextualidad en los cuentos de Darío IVán URIarTe (1986), «El intertexto como principio constructivo en los cuentos de $A z u l .$. y su proyección en la nueva narrativa latinoamericana", Revista Iberoamericana, 137, pp. 937-943. 
La ambientación que remite al mundo del primitivo cristianismo de los eremitas, nos sitúa en el terreno de lo maravilloso ${ }^{5}$. De este modo el cuento oscila desde lo maravilloso en su primera parte a lo fantástico en la segunda. El desierto constituye un lugar privilegiado para lo maravilloso medieval. El desierto de la imaginación cristiana es un lugar deshabitado, territorio peligroso, lugar de tentaciones y morada de los malos espíritus. Como señala Le Goff el desierto de los eremitas cristianos «se manifiesta como el lugar por excelencia de lo maravilloso; el asceta encuentra allí al demonio de manera inevitable, pues el demonio está en su casa en el desierto. Pero también el monje en cierta manera encuentra en el desierto al Dios que ha ido a buscar allí» ${ }^{6}$. Junto a esta imagen del desierto existe la que ve en él un refugio, en el que los animales salvajes se convierten en interlocutores de los anacoretas.

La erudición del sabio remite, por tanto, al mundo de lo maravilloso cristiano; en cambio, la segunda parte del cuento, de ambientación a la vez moderna y pagana, nos lleva al universo de lo fantástico. Lo fantástico supone una intromisión en el mundo cotidiano de un universo sobrenatural, existente en la tradición cultural, pero que no responde a la experiencia cotidiana. Se trata, pues, de un conflicto entre dos modelos de mundo diferentes. En cambio, en lo maravilloso exótico se relatan acontecimientos fuera de lo cotidiano sin presentarlos como tales, pues el receptor implícito no conoce las regiones o el tiempo en el que acaecen los sucesos. Por tanto, no existe en este caso un conflicto entre modelos de mundo. Conviene distinguir, por otra parte, lo maravilloso de los cuentos de hadas en el que el lector se encuentra desde el principio en un universo distinto del cotidiano, debiendo aceptarlo en virtud del pacto narrativo entre autor y lector, y el de los mirabilia medievales, que no nos sitúan en un universo diferente del nuestro ${ }^{7}$. La descripción de un animal exótico realmente existente,

5 También las historias de sátiros y monstruos atrapados por seres humanos y conducidos ante la presencia del rey suponen la transposición de tradiciones míticas anteriores. Baste recordar los precedentes de la captura de Sileno en la égloga VI de Virgilio y los paralelos de este tipo de historias en los cuentos maravillosos. Cf. V. PROPP $\left(1979^{2}\right)$, Las raíces históricas del cuento, Madrid, pp. 228-239; relatos que, a través de la influencia de Le Satyre (poema de La légende des siècles de VICTOR HUGO), encuentran su equivalente, actualizados y convertidos en imagen arquetípica, en $E l$ sátiro sordo, ante quien se presenta Orfeo, y El rey burgués, ante cuyo trono llevan una rara especie de hombre, un poeta. En el poema de V. Hugo el sátiro, salvaje y libidinoso, es conducido ante los dioses, que, divertidos por él, le invitan a cantar. Como el Sileno de Virgilio, el sátiro entonará un canto en el que se resume la historia de la tierra y de la humanidad, revelando paulatinamente su grandeza hasta mostrarse finalmente como Pan, el gran Todo.

- JACQues LE GofF $\left(1986^{2}\right)$, Lo maravilloso y lo cotidiano en el Occidente medieval. Barcelona, p. 28.

7 Cf. Tzvetan Todorov $\left(1974^{2}\right)$, Introducción a la literatura fantástica, Buenos Aires. Todorov define lo fantástico por la vacilación del lector implícito, mientras que lo maravilloso nos sitúa desde el principio en el terreno de lo sobrenatural; lo extraño constituiría el polo opuesto, en el 
como puede ser el hipopótamo o la jirafa, para el lector que pertenezca a un mundo no familiarizado con ellos resulta tan maravilloso como el de un ser fruto de la pura fantasía. Esta forma de lo maravilloso se configura ante todo como un universo de objetos.

La narración está regida enteramente por el paralelismo. El cuento consta de dos secuencias, cada una de las cuales tiene a su vez dos momentos distin$\operatorname{tos}^{8}$. Dicha estructura se organiza en torno a lo que Roland Barthes denomina "código hermenéutico»". La primera secuencia sirve para formular los elementos de dicho código narrativo que se resuelven en la secuencia final. Ya la secuencia inicial está dominada por el principio del paralelismo. Algunas de las correspondencias son evidentes:

- Lesbia afirma entre risas que desearía como amante a los sátiros o centauros.

- Incredulidad aparente de Lesbia hacia la existencia de dichos seres.

- El sabio sostiene que los sátiros, los faunos, los hipocentauros y las sirenas existen.

- Lesbia se ríe abiertamente.
- El poeta desea contemplar las desnudeces de las ninfas.

- Incredulidad del poeta sobre la existencia de las ninfas.

- Lesbia afirma que las ninfas existen y que el poeta las verá.

- Lesbia habla confidencialmente.

Los paralelismos continúan en la segunda secuencia del texto. La conexión entre ambas secuencias y entre los dos momentos de esta segunda parte del cuento es evidente:

que los hechos se explican finalmente de forma natural. Lo fantástico implica, pues, el conflicto entre modelos de mundo, mientras que lo maravilloso nos sitúa en un modelo de mundo alternativo (caso del cuento maravilloso), o en el caso de la literatura de mirabilia en un universo no familiar (pero que no es en principio distinto del del lector implícito); implica además, en la literatura actual, a diferencia de la medieval, un conflicto entre dos tipos de receptor: un receptor «ingenuo» para el que el modelo de mundo del texto no es distinto del nuestro, y un lector sofisticado, que conoce la diferencia. De ahí el efecto frecuente del conflicto, como en el cuento de Darío, entre un aparente cientifismo y el fondo fantástico, así como la degradación de los seres monstruosos al ser incorporados al modelo de mundo privilegiado como cotidiano.

${ }^{8}$ C. LE Bigot (1995), «Sobre un género modernista: los cuentos poéticos de Azul», en J. IsSOREl (ed.), El cisne y la paloma, Presses Univ. de Perpignan, pp. 83-114 (p. 91]) incluye este cuento entre los que tienen estructura de díptico.

${ }^{9}$ Con este código se refiere Barthes a la forma en que se centran, se plantean, se formulan, se retrasan o se descifran los enigmas que el relato terminará finalmente por desvelar. CF. BARTHES (1980), $S / Z$, Madrid, p. 14. 
- El poeta ve en el estanque de los cisnes una ninfa.

- Escucha una risa; la ninfa huye y queda burlado.
- Lesbia afirma que el poeta ha visto ninfas.

- Lesbia se ríe como una chiquilla traviesa.

En realidad el enigma planteado sobre la existencia de seres sobrenaturales no llega a ser nunca literalmente contestado. El relato admite una interpretación ambigua, según la norma habitual en la literatura fantástica ${ }^{10}$ y el lector no llega a saber si la imagen percibida es una mera ilusión del protagonista o si se trata de una realidad. Significativamente la formulación de la cuestión de la existencia de los seres mixtos de la mitología encuentra su motivación en el cuento en una discusión sobre obras de arte:

$Y$ de Fremiet se pasó a sus animales, a su cincel maestro, a dos perros de bronce que cerca de nosotros, uno buscaba la pista de la pieza, y otro, como mirando al cazador, alzaba el pescuezo y arbolaba la delgadez de su cola tiesa y erecta. ¿Quién habló de Mirón? El sabio, que recitó en griego el epigrama de Anacreonte: «Pastor, lleva a pastar más lejos tu boyada, no sea que creyendo que respira la vaca de Mirón la quieras llevar contigo...”

Se trata del tema tradicional de los epigramas helenísticos, que refleja el ideal ingenuo del arte como imitación precisa de la naturaleza ${ }^{11}$. Tomando pie de este tema Lesbia formula la afirmación que da ocasión al desarrollo del relato:

- iBah! Para mí los sátiros. Yo quisiera dar vida a mis bronces, y si esto fuese posible, mi amante sería uno de esos velludos semidioses. Os advierto que más que a los sátiros adoro a los centauros, y que me dejaria robar por uno de esos monstruos robustos, sólo por oír las quejas del engañado, que tocaría su flauta lleno de tristeza.

En la intervención de Lesbia hay un paso más con respecto a la descripción anterior de las estatuas: sugiere su animación. Las palabras de la mujer tienen indirectamente carácter proléptico, anticipando lo que va a suceder. El fauno que toca la flauta y su frustración son un equivalente del poeta. Más tarde el protagonista pasea por el ambiente idílico del parque:

10 Cf. T. TODOROV (op. cit.).

"Se trata concretamente de A.P. IX.715, atribuido a Anacreonte, uno de los numerosos ejemplos del tema en los epigramas helenísticos. 
Después, los altos árboles, los ramajes tupidos, llenos de mil abejeos, las estatuas en penumbra, los discóbolos de bronce, los gladiadores musculosos en sus soberbias posturas gímnicas, las glorietas perfumadas cubiertas de enredaderas, los pórticos, bellas imitaciones jónicas, cariátides todas blancas y lascivas, y vigorosos telamones del orden atlántico, con anchas espaldas y muslos gigantescos. Vagaba por el laberinto de tales encantos cuando oí un ruido, allá en lo oscuro de la arboleda, donde hay cisnes blancos como cincelados en alabastro...

El paseo por el parque sitúa al lector una vez más en un universo poblado de esculturas, donde incluso los blancos cisnes aparecen como cincelados en alabastro. De esta forma el milagro de la animación, puramente imaginado en la primera parte de la historia, se hace ahora realidad. Pero es el poder del ensueño del poeta el que da lugar a la encarnación de lo imaginario y de lo mítico, el que rompe la barrera entre realidad y fantasía. Era un día primaveral. Yo vagaba por el parque del castillo, con el aire de un soñador empedernido dice el narrador; y más tarde, cuando el poeta ha vislumbrado la aparición: Llegué más cerca. ¿Soñaba? 'Oh nunca!. Por otra parte, la ninfa es definida por el propio narrador como un ideal con vida y forma ${ }^{12}$.

La descripción de la ninfa recurre al procedimiento, característico de Darío, de la descomposición sinecdóquica:

Estaba en el centro del estanque, entre la quietud de los cisnes espantados, una ninfa, una verdadera ninfa, que hundía su carne rosa en el agua cristalina. La cadera, a flor de espuma, parecía a veces como dorada por la luz opaca que alcanzaba a llegar por las brechas de las hojas. ¡Ah! Yo vi lirios, rosas, nieve, oro; vi un ideal con vida y forma, y oi entre el burbujeo sonoro de la linfa herida, como una risa burlesca y armoniosa que me encendía la sangre.

12 JULJa UCEDa (1997), «El rostro interior (la imagen femenina en Rubén Darío)», Anthropos, 170-171, pp. 105-110 (p. 109]) incide en el simbolismo del agua estancada y en la fusión entre fantasía y realidad:

«En el conjunto concurren cuatro símbolos (...): el agua estancada (pero viva), la ninfa, los cisnes - teniendo muy en cuenta la pierna alba en la media negra-, y el poeta. el que mira, como víctima contempladora y fuera del conjunto. La quietud del agua del estanque parece actuar como espejo en el que se reflejan la ninfa y el cisne. Ella en posición vertical, él, horizontal siguiendo la línea del agua. Respecto a ésta, al agua como espejo, la dualidad ninfa/cisne puede interpretarse como imagen real e imagen reflejada: dos representaciones de la misma unidad (...). Mientras que la ninfa es una proyección del ánima masculina, el cisne es un 'ersatz' de la mujer desnuda. Es la desnudez permitida. Y paradojicamente no ha sido la ninfa (...) quien ha provocado la imagen erótica anticipada de la pierna alba y la media negra, sino el cisne, la verdadera mujer desnuda que, en el agua, es el reflejo de la ninfa (...). La pasividad del poeta no es gratuita. El cuento ha expresado en palabras el secreto interior que ha conocido su mirada». 
El mismo recurso descriptivo se encuentra en otro cuento, El rubí, en un cuadro poético que remite al mismo tipo de escena arquetípica:

Me hallé cerca de un arroyo, un río pequeño y claro donde las aguas charlaban diciéndose bromas cristalinas. Yo tenía sed. Quise beber ahí.. Ahora oid mejor.

Brazos, espaldas, senos desnudos, azucenas, rosas, panecillos de marfil coronados de cerezas; ecos de risas áureas, festivas; y allá, entre espumas, entre las linfas rosas, bajo las verdes ramas...

${ }_{-}$Ninfas?

-No, mujeres.

La técnica narrativa funde en ambos casos, mediante la focalización interna, la perspectiva temporal extradiegética del narrador-personaje que recuerda la historia al cabo de muchos años con la perspectiva intradiegética del personaje, resaltando así la subjetividad y la inseguridad de la percepción. En El rubí la pausa, la pregunta y la respuesta reflejan formalmente la expectación, al tiempo que establecen la equivalencia simbólica entre ninfa y mujer. Lo que desde el punto de vista de la verosimilitud del relato puede no ser más que un engaño de la percepción se convierte literariamente en realidad simbólica.

La descripción de la ninfa nos sitúa en una constelación formal y temática que recuerda el tema del nacimiento de Venus, que precisamente es evocado por el narrador de forma inmediata:

De pronto huyó la visión, surgió la ninfa del estanque, semejante a Citerea en su onda, y recogiendo sus cabellos, que goteaban brillantes, corrió por los rosales, tras las lilas y violetas, mas allá de los tupidos arbolares, hasta perderse, ;ay!, por un recodo.

El gesto de recogerse el cabello es el de Afrodita Anadiomena. Pero no es el único aspecto que recuerda las descripciones posteriores en la poesía de Rubén Darío del nacimiento de Afrodita. Baste mencionar la cadera que emerge del agua, la espuma y el contraste de colores: rosa, nieve, oro ${ }^{13}$. En cuanto a la

${ }^{13}$ El mismo tipo de artificio se encuentra, por ejemplo, en el soneto Le bain des nymphes de J.-M. de Heredia (en Les Trophées):

Ses compagnes, d'un bond, à l'appel du buccin, Dans l'onde jaillissante où s'ébat leur chair blanche Plongent, et de l'écume émergent une hanche, De clairs cheveux, un torse ou la rose d'un sein.

La descomposición sinecdóquica enlaza al final del soneto con la comparación de las ninfas atacadas por el fauno y los cisnes: 
risa que se escucha, asimilada al rumor del agua (oi entre el burbujeo sonoro de la linfa herida, como una risa burlesca y armoniosa), identificación que está reforzada por la equivalencia fónica ninfa - linfa, cabe recordar la descripción de la mujer que hace Hipea en el Coloquio de los centauros: y la risa / del agua que la brisa riza y el sol irisa. El mismo tipo de paronomasia se encuentra a propósito del motivo del baño en Palimpsesto. También el centauro Neso, cuando habla de Deyanira en el Coloquio dice ¡Oh rosas y alabastros!. En La ninfa son los cisnes los que son de alabastro.

Significativamente, cuando en la primera parte del relato el poeta manifiesta su deseo de contemplar las ninfas, evoca el mito de Acteón, mito arquetípico del tema: Yo desearía contemplar esas desnudeces de los bosques y de las fuentes, aunque como Acteón, fuese despedazado por los perros. ¡Pero las ninfas no existen! También en el poema Palimpsesto de Prosas profanas, que trata un tema afín, se menciona el mito de Acteón, mito que constituye la contrapartida de la escena del sátiro y la ninfa: la mirada del temor, frente a la mirada de la lujuria y el deseo ${ }^{14}$. Pero no será a Diana a quien vea el poeta en este caso, sino a Afrodita, encarnación opuesta de lo femenino.

El artificio de la descomposición sinecdóquica en la descripción de la belleza femenina permite fundir la visión de la aparición con la descripción del entorno en el que el arte y la naturaleza se unen ${ }^{15}$. Así, inmediatamente antes de la visión de la ninfa, se habla de los cisnes, que significativamente evocan formas femeninas: en el estanque donde hay cisnes blancos como cincelados en alabastro, y otros que tienen la mitad del cuello del color del ébano, como una pierna alba con media negra. La asociación poética cisne-mujer nos hace dudar sobre la descripción posterior. Del mismo modo, una vez que la ninfa ha huido (o que la iluminación momentánea del poeta ha desaparecido), el narrador de forma anular vuelve a retomar la imagen de los cisnes: y quedé yo, poeta lírico, fauno burlado viendo a las grandes aves alabastrinas como mofándose de mí, tendiéndome sus largos cuellos en cuyo extremo brillaba bruñida el ágata de sus picos. La imagen de las aves alabastrinas retoma la descripción anterior de los cisnes. Así la descomposición sinecdóquica de la descripción enlaza la ninfa con el entorno, con las flores (lirios, rosas), con la

Elles s'élancent. Tel, lorsqu'un corbeau sinistre

Croasse. sur le fleuve éperdument neigeux.

S'affarouche le vol des cygnes du Caÿstre.

${ }^{14}$ iAy del cuitado que a ver se atreve / Io que fué espanto para Acteón!

15 JULIA UCEDA a propósito de la iconización de la imagen femenina en RUBén DaRío cree percibir en su obra una ausencia paradójica (pues el motivo de la desnudez y del cuerpo femenino es corriente en Darío) del cuerpo femenino: «el cuerpo de la mujer es vestido de irrealidad o elidido, o diluido, en distintas armonías sacralizadoras, mistéricas.» (art. cit., p. 109-110). 
blancura de los cisnes, con el burbujeo del agua, con el juego de la luz sobre el estanque (oros).

Pero además la risa cristalina de la ninfa evoca inevitablemente el reír enigmático de Lesbia, motivo recurrente a lo largo del cuento. La risa es el rasgo más característico de la protagonista ${ }^{16}$. Su primera aparición en el cuento se asocia a la risa (Lesbia acabó de chupar su azúcar, y con una carcajada argentina...). Más tarde la oímos de nuevo reír (pero entre el coro de carcajadas se oia irresistible, encantadora, la de Lesbia, cuyo rostro encendido, de mujer hermosa, estaba como resplandeciente de placer). Sus gestos se asocian a los de un felino (Lesbia habia vuelto a llenar su copa de menta, y humedecía su lengua en el licor verde como lo haría un animal felino ${ }^{17}$ ), a una chiquilla a la que hacen cosquillas: Lesbia se agitaba como una chicuela a quien hiciesen cosquillas. Al final del cuento reaparecerá el motivo: y ella me miraba como una gata, y se reia como una chiquilla a quien se le hiciesen cosquillas $^{18}$.

De este modo, la risa de Lesbia se transforma en la risa cristalina. ¿Es Lesbia, o su imagen transfigurada por la ensoñación, lo que en realidad ve el poeta? No sólo la ninfa se ríe (y el agua), sino que los cisnes parecen burlarse del poeta: fauno burlado viendo a las grandes aves alabastrinas como mofándose de $m i^{19}$.

in El nombre Lesbia se asocia inevitablemente a través de la Lesbia de CATUlLL MENDÉS a la Lesbia catuliana. cuya risa ambigua constituye el motivo del que parten dos epigramas del poeta latino ( 83 y 92). La ambientación (la elegante reunión, la risa. las líquidas transparencias de las bebidas alcohólicas etc.) son características de la obra de DARIO. Cf., por ejemplo, los poemas Era un aire suave y Garçonniere de Prosas profanas y la risa en Divagación.

17 En la presentación del escenario del cuento el narrador ha dicho: Presidía nuestra Aspasia, quien a la sazón se entretenía en chupar. como una niña golosa. un terrón de azúcar húmedo.

${ }^{18}$ La imagen reaparece en La muerte de la emperatriz de China, donde se habla de la viudita Andrea, que al reir sacaba la punta de la lengua, roja y felina, entre sus dientes brillantes y marfilados. El propio Dario dice de la Eulalia de Era un aire suave... en Historia de mis libros: el abate joven de los madrigales y el vizconde rubio de los desafios, ante Eulalia que rie, mantiene la secular felinidad femenina contra el viril rendido; Eva, Judith u Ofelia, peores que todas las «sufragettes».

14 J. P. BRownLow (1989), «La ironía estética de Darío: humor y discrepancia en los cuentos de Azuln, Revista Iberoamericana, 146-7. pp. 377-393. afirma a propósito de la risa de la protagonista: «El cuento es un contrajuego de realismo y fantasía en el que (...) la risa estorba la ilusión estética para dejar que turbe la ironía. La risa sarcástica de Lesbia señala la presencia de aquella ironía. porque parece convertir el cuento francés en una burla modernista del poeta y del lector. La risa es la confirmación de la inautenticidad de la visión. la cual ha sido artificio elaborado para la diversión de la compañía. El poeta, teniendo una sed de ilusión infinita, prefiere seguir con la ilusión, a pesar de las ironías que la ilusión implica. La mujer nunca deja de ser admirada y admirable, porque su crueldad inspira a la vez amargura romántica y deleite estético. El gozo de los poetas de Dario es siempre la alquimia perversa de aquella combinación. 
En la primera parte del cuento la mujer se burla de las afirmaciones del sabio, manifestando su incredulidad. En un momento dado, tras la referencia erudita a un monstruo con cabeza de perro, Lesbia se burla del siguiente modo:

- ¿Colombine!-gritó Lesbia. Y llegó Colombine; una falderilla que parecía un copo de algodón. Tomóla su ama, y entre las explosiones de risas de todos: 'Toma, el monstruo que tenía tu cara!

$Y$ le dio un beso en la boca, mientras el animal se estremecia e inflaba las narices como lleno de voluptuosidad.

Este episodio aparentemente anodino tiene un carácter de irónica puesta en abismo en el contexto del cuento. El monstruo mítico se ve degradado al nivel de un perrillo faldero.

En el paralelismo que rige el desarrollo de las dos secuencias del relato, se contraponen, por una parte, el personaje del poeta y el del sabio (el erudito burgués, que tiene noticia por su erudición de lo que el poeta percibe por intuición), y el poeta y Lesbia, por otra. Cuando el poeta manifiesta sus deseos imposibles, Lesbia se dirige a él confidencialmente: -iY qué!-dijo Lesbia, quemándome con sus ojos de faunesa y con voz callada para que sólo yo la oyera- ;Las ninfas existen, tú las verás! Cuando el poeta tiene su visión reaparecen los mismos motivos. La risa de la ninfa quema como el fuego (en contraste con el agua, según la tradicional imagen). El poeta, por su parte, es comparado con el fauno tras la huida de la ninfa: y quedé yo, poeta lírico, fauno burlado...

\section{Venus - Perséfone: $E l$ rubi}

La historia de El Rubí gira en torno a la joya y su simbolismo, que es paralelo al del oro en Darío. En La canción del oro, otro de los cuentos poéticos de $A z u l . .$. el mendigo entona las alabanzas del oro, en una letanía a la vez irónica y poética, lírica y desgarrada, que gira en torno a los valores sociales y simbólicos del oro ${ }^{20}$. El oro se asocia al sol:

Cantemos al oro, rey del mundo, que lleva dicha y luz por donde va, como los fragmentos de un sol despedazado.

Cantemos el oro, que nace del vientre fecundo de la madre tierra; inmenso tesoro, leche de ubre gigantesca.

21) Cf. sobre el doble código al que responden este tipo de imágenes (o los dos registros de un mismo código modernista) el estudio de 1. A. Schulman (1997), «El modemismo de Rubén Darío: la otra dimensión", Anthropos, 170-171, pp. 40-51. Esta dualidad está en la base de la ironía de la poesía de Rubén Darío, presente inevitablemente en muchas de sus más líricas efusiones. Cf. sobre la ironía en los cuentos de Azul... B. SEGALL (1966), "The Function of Irony in El rey burgués». Hispania, 49, pp. 223-227, y J.P. BROWNLOW (art. cit.). 
Esta asociación es de raíz alquímica; temática que se encuentra ya en la escena inicial del cuento:

- iAh, sabios de la Edad Media! „Ah. Alberto el Grande, Averroes, Raimundo Lulio! Vosotros no pudisteis ver brillar el gran sol de la piedra filosofal, y he aqui que sin estudiar las fórmulas aristotélicas, sin saber cábala y nigromancia, llega un hombre del siglo décimonono a formar a la luz del día lo que nosotros fabricamos en nues. tros subterráneos.

El oro que nace de las entrañas de la tierra es el equivalente terreno del sol, como fragmento desgajado del sol o como producto natural de la tierra que aspira así a lo celeste. La misma simbología, pero en esta ocasión con referencia a las joyas y no al oro, es clave en $E l$ rubí, donde se dice: El pavimento de mi taller se asemejaba a los restos de un sol hecho trizas; y antes se ha hablado de un diamante inmenso que brillaba como un astro. El rubí, como el oro, se asocia al sol, pues está hecho de rayos del poniente solidificados. Es un fragmento del iris y también el tesoro rubicundo de lo hondo del globo. En Bouquet un manojo de flores es comparado con un pedazo de iris hecho trizas. También en Acuarela reaparece el mismo motivo: Mostraba Mary su falda llena como de iris hechos trizas, que revolvía con sus manos gráciles de ninfa, mientras sonriendo su linda boca purpurada, sus ojos abiertos en redondo dejaban ver un color de lapislázuli y una humedad radiosa.

A lo largo de La canción del oro, auténtico poema en prosa, se despliega todo el abanico temático basado en el simbolismo alquímico del oro y de las joyas: el oro como contrapartida del sol, nacido en las entrañas de la tierra, el oro como equivalente del hombre:

Cantemos el oro, calificado de vil por los hambrientos; hermano del carbón, oro negro que incuba el diamante; rey de la mina, donde el hombre lucha y la roca se desgarra; poderoso en el poniente donde se tiñe de sangre; carne de ídolo, tela de que Fidias hace el traje de Minerva (...).

Cantemos el oro (...) en el lauro que ciñe las cabezas luminosas, en la copa del festín dionisiaco, en el rayo del astro y en el champaña que burbujea como una disolución de topacios hirvientes (...).

Cantemos el oro, purificado por el fuego, como el hombre por el sufrimiento; mordido por la lima, como el hombre por la envidia; golpeado por el martillo, como el hombre por la necesidad (...).

Cantemos el oro, dios becerro, tuétano de roca misterioso y callado en su entraña, y bullicioso cuando brota a pleno sol y a toda vida, sonante como un coro de tímpanos; feto de astros, residuo de luz, encarnación de éter. 
Cantemos el oro, hecho sol, enamorado de la noche, cuya camisa de crespón riega de estrellas brillantes, después del último beso, como una gran muchedumbre de libras esterlinas.

La concepción del oro como equivalente en la tierra de los astros culmina en la comparación final, que une el simbolismo elevado del oro con el rechazo de los valores burgueses, haciendo del oro el enamorado de la noche, cuya camisa riega con monedas, como generoso amante. En la tradición esotérica y alquímica el sol es una imagen de Dios, que se refleja en el corazón del hombre lo mismo que el oro es su reflejo en la tierra. Cristo como lapis, se identifica con la piedra filosofal $u$ oro alquímico. El tallado de las piedras preciosas y el de las estatuas constituye, por otra parte, un símbolo ascético bien conocido: los golpes del artista (Dios) purifican el alma humana a través del dolor.

De este modo, la joya nacida de la tierra no puede compararse con la creada artificialmente, pues las verdaderas riquezas se engendran en las simas interiores, son producto del tiempo lento y del sufrimiento ${ }^{21}$; es el fundamento de la metáfora alquímica relativa al carácter del sabio ${ }^{22}$. La conclusión del cuento con la moraleja puesta en boca de Puck resalta este contraste entre la autenticidad infalsificable de lo artístico y sus sucedáneos. Puck dice de la tierra y de la mujer: «de tu vientre moreno brota la savia de los troncos robustos, y el oro y el agua diamantina, y la casta flor de lis. ;Lo puro, lo fuerte, lo infalsificable! ¿Y tu, Mujer, eres espíritu y carne, toda amor!"

En el desarrollo del cuento existe un paralelismo entre el robo de la piedra artificial por Puck y el rapto de la mujer por el gnomo. De este modo la narración incluida refleja el marco narrativo, según la técnica de la puesta en abismo ${ }^{23}$.

${ }^{21}$ En un pasaje de La lámpara maravillosa de VALLF-INCLÁn se dice: En todas las cosas duerme un poder de evocaciones eróticas. Algunas parecen despertarse apenas nos aproximamos. otras tardan en revelarse, otras aún no se revelaron, otras no se revelarán jamás. Pero si un dia pudiésemos conocerlas integramente, las veriamos enlazarse en sucesión matemática y concretarse en un solo impulso de amor, como las entrañas de la tierra concretan en la claridad de los cristales el esfuerzo de miles de años.

22 Cf. P. Gomez Bedate (1997), «Las joyas de Rubén Darío», Anthropos, 170-171, pp. 68-75.

23 P. W. Dixon (1986), «Rebirth Patterns in Several Short Stories by Rubén Darío: A Distinctive Feature», Hispanic Journal, 7, pp. 87-91 (p. 901) señala la relación entre El rubi y el arquetipo del renacimiento que este autor descubre en numerosos cuentos de Dario: «Two rebirth patterns are thus enacted in El rubi. One, encompassing the structure of the whole story, involves Puck. who descends into the earth, hears the patriarch's words, and surfaces again into the morning with renewed hope and assurance about the value of the true ruby. A second, contained within the first, involves a woman who does down into the tomb (and womb) of the earth, perishes there, but with here blood gives birth to precious stones. Although the exterior rebirth pattern does not involve a transfer of life from one object to another, the interior one does». 
La narración de Puck del robo se inicia con una exclamación: -iOh, Tierra! ¡Oh, Mujer! Desde el tiempo en que veía a Titania no he sido sino un esclavo de la una, un adorador casi místico de la otra. Del mismo modo, es Puck el encargado en el epílogo de extraer la moraleja simbólica de la historia del gnomo, mediante el recurso poético del ritornelo:

\section{-Tierra... Mujer...}

«Porque tú, ¡Oh madre Tierra!, eres grande, fecunda, de seno inextinguible y sacro: $y$ de tu vientre moreno brota la savia de los troncos robustos ${ }^{24}$, y el oro y el agua diamantina, y la casta flor de lis. iLo puro, lo fuerte, lo infalsificable! iY tu, Mujer, eres espíritu y carne, toda amor!»

La identificación Tierra - Mujer (las mayúsculas son significativas) constituye una de las claves de la narración. Cuando el gnomo descubre a las bañistas, el relato es interrumpido por un breve diálogo que insiste una vez más en la mujer y en el que la brevedad asocia metafóricamente ambos términos:¿Ninfas? -No, mujeres.

La anécdota de El rubí resulta especialmente significativa si la comparamos con los mitos relativos a dos divinidades que encarnan dos arquetipos diferentes de lo femenino: Venus y Perséfone (o mejor dicho, la Perséfone/Psique de la tradición simbólica y literaria que hereda Darío) ${ }^{25}$. Se trata, sin embargo, en este caso más bien de mitología subyacente. Inútil resulta precisar que no nos referimos a una influencia directa del mito sobre el cuento, sino más bien a la presencia en el relato de modelos arquetípicos, que corresponden a los mitos tradicionales y que pueden, por consiguiente, ser usados como interpretantes intertextuales, útiles a la hora de entender la obra.

La historia de Perséfone plantea un contraste entre las distintas regiones del universo mítico: el mundo inferior, el celeste y el intermedio, la tierra habitada

${ }^{24}$ Cf. en La canción del oro: Cantemos el oro. que nace del vientre fecundo de la madre tierra; inmenso tesoro. leche de ubre gigantesca. Esta imaginería de la germinación recuerda la que se encuentra, por ejemplo. en La fiesta de Roma, asociada a la vinculación con la tierra y con la figura de Venus.

25 La presentación del rubí resulta significativa al respecto: El cuerpo del delito estaba allí, en el centro de la gruta, sobre una gran roca de oro; un pequeño rubi, redondo, un tanto reluciente. como un grano de granada al sol. La comparación aparece en el capítulo VII de La catedral de Huysmans, auténtico tratado del simbolismo medieval de los colores y de las piedras preciosas, pero referido a otra piedra: La sardónice, semejante al grano sangriento de una granada. Cf. J. K. Huysmans, La catedral, Madrid, trad. esp. 1961, p. 180. La comparación con el grano de granada, natural a propósito del rubí, resulta interesante. Porque el grano de granada tiene una especial importancia en el simbolismo de un mito clásico, el de Perséfone. Perséfone no puede regresar junto a su madre, por haber comido precisamente un grano de granada. 
por los seres humanos. Los seres del mundo inferior se rebelan contra los del universo superior. En el cuento de Darío los gnomos salen a la superficie: $-U n$ día, nosotros, los escuadrones que tenemos a nuestro cargo las minas de diamantes, tuvimos una huelga que conmovió toda la tierra, y salimos en fuga por los cráteres de los volcanes.

También los volcanes juegan un papel en el mito de Perséfone, cuyo rapto se sitúa tradicionalmente en Sicilia. En Ovidio el soberano de los infiernos sale a la superficie debido a su temor a causa de los temblores de tierra provocados por los titanes sepultados. Los motivos titánicos desempeñan una importante función en las dos versiones clásicas del mito, la de las Metamorfosis de Ovidio y la de Claudiano, pues la titanomaquia constituye un reflejo en el pasado de la rebelión actual del mundo inferior y el mito del rapto de Perséfone se inscribe dentro de los mitos que explican la ordenación del mundo. Los autores clásicos se servirán continuamente de dichos motivos de acuerdo con la técnica de la puesta en abismo.

La época en que el rapto se produce es en el cuento de Darío la primavera. El ascenso al mundo superior de la luz va así acompañado del deslumbramiento de la naturaleza en todo su esplendor, pletórica de color y de mágicos sonidos:

Estaba el monte armónico y florido, lleno de trinos y de abejas; era una grande y santa nupcia la que celebraba la luz, en el árbol la savia ardia profundamente, y en el animal todo era estremecimiento o balido o cántico, y en el gnomo habia risa o placer.

Nupcias de la luz, placer de la naturaleza ${ }^{25}$. La diosa está cogiendo flores, cuando es raptada, flores que simbolizan su virginidad y su destino de muerte. La contemplación de las bañistas remite, como hemos visto, a otra escena arquetípica, la del fauno espiando a las ninfas. En el mito de Perséfone Hades regresa a su reino inferior haciendo que la tierra se abra. Lo mismo ocurre en el caso del gnomo: Y a ella, a la hermosa, a la mujer, la así de la cintura, con este brazo antes tan musculoso; gritó, golpeé el suelo; descendimos. Arriba quedó el asombro, abajo el gnomo soberbio y vencedor.

${ }^{26}$ La metáfora es semejante a las que aparecen en otros cuadros descriptivos en la obra de DARío. Así ocurte en Paisaje: Y arriba el cielo con su inmensidad y con su fiesta de nubes, plumas de oro, alas de fuego, vellones de púrpura. fondos azules, flordelisados de ópalo, derramaba la magnificencia de su pompa, la soberbia de su grandeza augusta; y en La fiesta de Roma: Una gloria vesperal empurpuraba la fiesta del cielo, y caía, regia, sobre Roma. Se hubiese pensado en una decoración voluntaria de la naturaleza en homenaje a la ciudad divina. Doraba, roja. la luz. las lejanías; cata a rayos oblicuos sobre los jardines que en lo pintoresco de la ribera atraían con la alegría de sus flores, de sus mujeres y de su vino lesbiano. 
Naturalmente en el cuento de Darío no existe la madre añorada, que busca a su hija perdida; el papel de la madre lo cumple en este caso el enamorado. Tampoco existe en el mito de Perséfone metamorfosis. La transformación que da origen al rubí constituye precisamente el núcleo argumental del relato:

De su lecho, de su mansión más luminosa y rica que la de todas las reinas del Oriente, habia volado fugitiva, desesperada, la amada mía, la mujer robada. ¡Ay! Y queriendo huir por el agujero abierto por mi maza de granito, desnuda y bella, destrozó su cuerpo blanco y suave como de azahar y mármol y rosa, en los filos de los diamantes rotos. Heridos sus costados, chorreaba la sangre; los quejidos eran conmovedores hasta las lágrimas. ;Oh dolor!

Yo desperté, la tomé en mis brazos, la di mis besos más ardientes; mas la sangre corría inundando el recinto, y la gran masa diamantina se teñía de grana.

Me parecía que sentia, al darla un beso, un perfume salido de aquella boca encendida: el alma; el cuerpo quedó inerte.

Cuando el gran patriarca nuestro, el centenario semidiós de las entrañas terrestres, pasó por allí, encontró aquella muchedumbre de diamantes rojos...

La transformación de los diamantes teñidos por el rojo de la sangre está cuidadosamente preparada. El gnomo está trabajando rompiendo un inmenso diamante:

El pavimento de mi taller se asemejaba a los restos de un sol hecho trizas. La mujer descansaba a un lado, rosa de carne entre maceteros de zafir, emperatriz del oro, en un lecho de cristal de roca, toda desnuda y espléndida como una diosa.

Hay un evidente paralelismo entre las joyas y la mujer, que descansa en un lecho de cristal de roca, descripción que se podría aplicar a una joya. Por otra parte, la descripción sinecdóquica rosa de carne experimenta un significativo desarrollo, a partir de la polisemia del término rosa; el color rosa, rasgo sinecdóquico de la descripción de la mujer se convierte en una flor, la rosa, entre maceteros de zafir; las joyas se identifican esta vez con flores. La mujer-rosa es emperatriz del oro, como la rosa es la reina de las flores.

La imagen de la mujer, desnuda entre las joyas comparadas con flores, espléndida como una diosa es la de una Venus desnuda, pero también la de una Bella Durmiente, Perséfone/Psique adormecida entre las flores con el sueño de la muerte. 
Pero la mujer sigue amando a un hombre:

Ella amaba a un hombre, y desde su prisión le enviaba sus suspiros. Estos pasaban los poros de la corteza terrestre y llegaban a él; y él, amándola también, besaba las rosas de cierto jardín; y ella, la enamorada, tenía - yo lo notaba - convulsiones súbitas en que estiraba los labios rosados y frescos como pétalos de centifolia ${ }^{27}$ ¿ Cómo ambos se sentían? Con ser quien soy no lo sé.

Había acabado yo mi trabajo: un gran montón de diamantes hechos en un día; la tierra abria sus grietas de granito como labios con sed, esperando el brillante despedazamiento del rico cristal.

El enamorado besa las rosas, que como hemos visto, son el equivalente de la amada. En correspondencia ella estiraba sus labios rosados y frescos como pétalos de centifolia. De esta forma, la mujer sigue siendo asimilada a una flor y esta a un beso.

Existe, por otra parte, un paralelismo entre la imagen de la mujer que forma un beso con sus labios y la sed de la tierra que anhela los diamantes despedazados por el gnomo: la tierra abría sus grietas de granito como labios con sed, esperando el brillante despedazamiento del rico cristal. Los pétalos de la centifolia anticipan el destino de la mujer y sugieren las múltiples caras de las joyas talladas. De esta forma, cuando a la hora de describir su muerte reaparecen los elementos tópicos de la descripción femenina que ya hemos visto a propósito de La ninfa, estos cobran un valor totalmente nuevo: desnuda y bella, destrozó su cuerpo blanco y suave como de azahar y mármol y rosa.

El motivo de la metamorfosis, la transformación a través del dolor, proviene evidentemente, como ya hemos señalado, de la temática alquímica. En la alquimia la tierra es un crisol donde, lentamente, los minerales maduran, donde el bronce se convierte en oro. Pero la sangre que tiñe de rojo los diamantes convirtiéndolos en rubíes enlaza también, por otra parte, con un motivo tradicional, reiterado en las obras posteriores de Darío: la metamorfosis de la rosa. Parecido es el motivo que aparecerá en el poema La rosa niña de Canto a la Argentina y otros poemas. Los últimos versos del poema narran la metamorfosis de la niña deseosa de ofrecer un regalo al niño Jesús:

Se puso rosada, rosada, rosada... ante la mirada del niño Jesús. (Felízmente que era su madrina un hada, de Anatole France o el doctor Mandrús.)

${ }^{27} \mathrm{Cf}$. en El año que viene siempre es azul: las abejas confundian sus labios con una fresca centifolia. Cf. En la batalla de las flores: en tanto que las mejillas de las mujeres sean tan frescas como las centifolias. 
¿Qué dar a ese niño, qué dar sino ella!

¿Qué dar a ese tierno, divino Señor?

Le hubiera ofrecido la mágica estrella,

la de Baltasar, Gaspar y Melchor...

Mas a los influjos del hada amorosa, que supo el secreto de aquel corazón, se fue convirtiendo poco a poco en rosa, en rosa más bella que las de Sarón.

La metamorfosis fué santa aquel día (la sombra lejana de Ovidio aplaudía), pues la dulce niña ofreció al Señor, que le agradecía y le sonreía, en la melodía de la Epifanía, su cuerpo hecho pétalos y su alma hecha color.

La rosa es en este caso el equivalente de la estrella (Le hubiera ofrecido la mágica estrella) y la expresión poética del alma, de acuerdo con el simbolismo habitual en Darío ( $s u$ alma hecha color). Similar a la transformación de la rosa niña son las lágrimas del hermano Longinos en Cuento de Noche Buena, pero en este caso falta la metamorfosis y el tema corresponde a un motivo característico del cuento maravilloso, el de la princesa cuyas palabras son flores y sus lágrimas perlas: $Y$ he aqui que los reyes de Oriente vieron brotar de los labios de Longinos las rosas de sus oraciones, cuyo olor superaba a todos los ungüentos y resinas; y caer de sus ojos copiosísimas lágrimas que se convertían en los más radiosos diamantes por obra de la superior magia del amor y de la fe. El motivo aparece además en un contexto similar al de La rosa niña. También Longinos, emblema de la fe ingenua, se une al cortejo de los reyes magos para adorar al niño Dios y una vez más las oraciones y las lágrimas substituyen a los regalos que la falta de recursos le impiden hacer.

El mismo motivo aparece en el cuento En la batalla de las flores:

En un corso como éste, las flores suelen llevar malos mensajes, y suelen ser mentirosas. He visto a un caballero enviar un ramillete al cual había confiado esta frase: «Yo te amo», cuando en su corazón todo el fuego amoroso es ya pura ceniza. Una niña gentil y vivaz ha encargado a cuatro azahares la misma respuesta... Y una rosa se ha puesto más roja de lo que era al llevar tan extraña declaración ${ }^{2 R}$.

28. En El sátiro sordo los efectos del canto del ruiseñor, que anticipan la figura de Orfeo y el efecto de su música incluyen el enrojecimiento de las rosas: Filomena llegaba a cantarle (...) canciones que hacian detenerse los arrovos y enrojecerse las rosas pálidas. 
Se trata de una variante más del mismo motivo. La rosa está íntimamente ligada a Venus; nace en la mitología al mismo tiempo que Venus o bien de la sangre de Venus o de la de su amante Adonis ${ }^{29}$. A partir de esta base mitológica se desarrolla el concepto que hemos visto en los textos citados. Este tema tenía una larga tradición en la literatura occidental. Aparece ya en los epigramas de la Antología Latina con respecto al nacimiento de la rosa ${ }^{30}$. Las rosas blancas enrojecen de verguienza por haber herido a la diosa Venus, al tiempo que la sangre de la diosa tiñe las rosas ${ }^{31}$. Se trata en este caso de una variante del motivo del instrumento inocente de un crimen, dentro del tema más general de la simpatía de los objetos.

El tema, del que existen numerosas versiones de los siglos XVI y XVII, se basa en el simbolismo de la rosa y de los colores. El color rosa es mezcla del blanco, símbolo de la pureza y de la virginidad, y del rojo. El rojo, vinculado a la sangre, es ambivalente, pues está asociado tanto al pudor como al fuego y a la pasión. De esta forma tales poemas explotan la aparente ambigüedad simbólica, que constituye poéticamente, junto a la ambivalencia flor - espinas, el correlato objetivo de la naturaleza femenina, encarnada míticamente en la figura de Venus. A partir de este motivo de base existen numerosas variaciones ${ }^{32}$ y también, como en el caso de Darío, versiones a lo divino, en que la metamorfosis se

${ }^{29}$ En Bouquet se habla del nacimiento de la rosa: Cuando Venus nació en las espumas (...). Cibeles hizo brotar el rosal primitivo. La propia Afrodita florece de la espuma del mar. Cf. sobre la metáfora florecer aplicada al nacimiento de Venus A. MARAsso (op. cit, p. 64).

30) Por ejemplo, Draconcio (A.L. 874, De origine rosarum):

Alma Venus quondam dum Martis vitat amores

Et pedibus nudis florea prata premit.

Sacrilega placidas irrepsit spina per herbas

Et tenero plantas vulnere mox lacerat.

Funditur inde cruor; vestitur spina rubore;

Quae scelus admisit, munus odoris habet.

Sanguine cuncta rubent croceos dumeta per agros

Et sancit vepres astra imitata rosa.

Quid prodest. Cypris. Martem fugisse cruentum.

Cum tibi puniceo sanguine planta madet?

Sanguineis Cytherea genis, sic crimina punis,

Mordacem ut spinam flammea gemma tegat?

Sic decuit doluisse deam, sic numen amorum.

Vindicet ut blandis vulnera muneribus.

3) En Las tres reinas magas, al describir el reino de Amatunte (o lo que es lo mismo, de Afrodita), aparece una variante del mismo tema: es el país en donde la prodigiosa carne femenina, al mostrarse en su pagana y natural desnudez, tiñe de rosa los enternecedores crepúsculos.

${ }^{32}$ Por ejemplo, a la versión tradicional se añade la del rubor de Venus o de una ninfa sorprendida por el sátiro, que contagia su color a las flores; tema más frecuentemente asociado con el mirto, también ligado tradicionalmente a Afrodita. 
justifica no por referencia al universo mitológico y pagano, sino al cristiano y en las que, por ejemplo, el instrumento de tortura que hiere al santo o a Cristo enrojece de vergüenza (o sea, se tiñe del rojo de la sangre) ${ }^{33}$.

De esta forma los distintos planos de significación presentes en el texto convergen para conferirle un significado único. La temática alquímica se conjuga fácilmente con el componente mitológico subyacente del texto. Las peripecias de Perséfone pueden ser concebidas como la historia del alma, de Psique, que sufre un descensus ad inferos, una experiencia de muerte en vida, un descenso a las profundidades de sí mismo que encierran un secreto, un críptico conocimiento. Por otra parte, en cuanto diosa de la naturaleza implica el tema de la generación (lo que conecta con los motivos de las flores y de la primavera); pero el renacimiento del alma es de orden diferente y presupone la alienación social y la profundización en sí mismo, la experiencia de la muerte. La temática de la simpatía de la naturaleza y del nacimiento del rubí responde también, como hemos visto, a una tradición literaria, reforzando la asociación poética entre las flores, la mujer y las joyas.

El cuento puede leerse, por consiguiente, como una alegoría referente al alma humana, pero también al arte puro, a la búsqueda de un ideal. El arte puro, fruto del sufrimiento, cristalización del alma humana, se contrapone al prosaísmo burgués. La figura de Puck enlaza este cuento con una mitología sackespeareana muy grata a Darío que reaparece, por ejemplo, en El velo de la reina Mab y en una fantasía humorística como El linchamiento de Puck, donde el travieso duende sufre un destino similar al del Eros crucificado o azotado de la literatura clásica ${ }^{34}$.

La dualidad rosa - rubí, Venus - Perséfone (o lo que es lo mismo, la dualidad de la mujer como ánima), preside el cuento ${ }^{35}$. Ambas diosas están estrechamente asociadas. La granada del mito tiene su equivalente simbólico en la rosa. Pues la rosa no sólo encarna la naturaleza femenina, está también, en cuanto simboliza el alma, asociada a la muerte. Las flores relacionadas con Afrodita se

${ }^{33}$ Famoso fue el epigrama del poeta neolatino inglés R. CRASHAw sobre el milagro de la transformación del agua en vino en las bodas de Caná:

Unde rubor vestris et non sua purpura lymphis?

Quae rosa mirantes tam nova mutat aquas?

Numen (convivae) praesens agnoscite Numen:

Nympha pudica Deum vidit, et erubuit.

${ }^{34}$ Cf. sobre el papel de Puck en El rubi J.P. Brownlow (art. cit., p. 386): «La sonrisa del gnomo nos advierte de que en el cuento no se pasa nunca de los límites del artificio estético. Ironía y sinceridad se subordinan al objeto de arte, al rubí mismo, que se crea (...) de la fusión del sentimiento del poeta-hacedor con la forma ideal femenina».

35 Cf. para la recurrencia de símbolos de la interioridad en otros cuentos de DARío L. MuÑoz G., «La interioridad en los cuentos de Rubén Darío» (1967), Atenea, 415-416, pp. 173-192. 
encuentran igualmente en las praderas del más allá. Perséfone no puede regresar a la vida por haber comido unos granos de granada. La granada está también asociada a Afrodita (en relación con la fertilidad y el matrimonio). Por otra parte, la función de la granada de Perséfone es desempeñada a veces en la literatura por las flores y por la rosa. En los cuentos del tipo La bella y la bestia, por ejemplo, es el robo de una flor lo que condena a la protagonista a permanecer en el palacio encantado. En El asno de oro de Apuleyo, en cambio, las rosas permitirán al asno salir del estado de muerte en vida que supone su metamorfosis animal.

La asociación flor - estrella, que hemos visto en La rosa niña y en El rubí se encuentra en otros textos de Darío. Así ocurre en Historia de un picaflor, donde dicen las flores: -Entre las estrellas y las mujeres, son éstas las más terribles rivales. ;Aquellas están tan lejos...; en Bouquet se habla de amores misteriosos de estrellas y de lirios; en El sátiro sordo: Una vez voló un clavel de su tallo hecho mariposa roja, y una estrella descendió fascinada y se torno flor de lis (asociación a la que se añade la de flor y la mariposa, otro símbolo del alma); en El coloquio de los centauros la mujer es envidia de las flores y celos de los astros. Flores y joyas se asocian con el ojo y la mirada. Así en Bouquet la rosa es ojo de Flora; la rosa de Bengala viene de un lugar de sueños, de perlas, de ojos ardientes. En Por el Rhin las pupilas de Margarita miran con la franqueza de una dulce piedra preciosa, o de un ágata rara como las piedras fabulosas de los cuentos, que miraban como ojos. En el Coloquio de los centauros, donde se habla largamente de la unidad esencial existente bajo la aparente multiplicidad de la naturaleza, hay un pasaje en torno a las piedras preciosas ${ }^{36}$ :

He visto, entonces raros ojos fijos en mi:

los vivos ojos rojos del alma del rubi;

los ojos luminosos del alma del topacio

y los de la esmeralda que del azul espacio

la maravilla imitan; los ojos de las gemas

de brillos peregrinos y mágicos emblemas.

Mito y FANTASÍA

En Historia de mis libros Rubén Darío se refiere a la interpretación de El rubi. Según él, El rubi es otro cuento a la manera parisiense. Un «mito», dice

in Cf para las implicaciones de este pasaje del Coloquio dentro de la estética del parnasianismo y del simbolismo M.-J. FAURIE (1966), Le modernisme hispano-américain et ses sources françaises, Paris, pp. 33-38. 
Valera. Una fantasía primaveral, más bien; lo propio que «El palacio del sol». Darío mismo hablará de Mito a propósito del Coloquio de los centauros. ¿Mito o fantasía? Ambos términos (en la acepción en que aquí se utilizan) enfatizan la imaginación creadora del artista. La mente del artista se escinde así entre su propia imaginación y la contemplación distanciada de tales representaciones como figuras que adquieren una especie de independencia con respecto a su creador. El término mito, en este sentido especial (semejante al uso del vocablo cuando hablamos de los mitos platónicos) implica, sin embargo, un carácter arquetípico y tradicional, frente a la mayor libertad creativa de la fantasía.

¿Tiene El rubí carácter alegórico? Ciertamente el cuento expresa el conflicto entre el creador y la sociedad burguesa que lo rodea, al igual que otros cuentos de $A z u l . .$. , así como la naturaleza especial y única de la obra artística. La alegoría implica habitualmente, por otra parte, elementos fantásticos. El problema concierne al papel de la ficción en la obra literaria. Si en una narración literaria conviven elementos verosímiles, que no alteran el modelo de mundo privilegiado que identificamos con la realidad, y elementos sobrenaturales (o que no responden a nuestro modelo de mundo), los elementos verosímiles se integran (en el caso de un relato maravilloso o fantástico) en el modelo de mundo alternativo, siendo este el modelo de mundo dominante en el texto. En cambio, el relato realista se define por la exclusión de elementos inverosímiles. Ahora bien, en el caso de la alegoría (o de la sátira) la dinámica de la ficción es precisamente la opuesta. Es decir, si el universo ficcional incluye elementos que no responden a nuestro modelo del mundo, deben ser reducidos y recuperados, como una violación evidente de la máxima conversacional de cualidad, que prohíbe afirmar lo evidentemente falso o aquello de lo que carecemos de pruebas. La ficción tiene entonces carácter figurativo.

Esto excluye entender $E l$ rubí como alegoría en sentido estricto. En la alegoría el universo ficticio se convierte en signo. La ficción adquiere carácter figurativo. Los acontecimientos narrados actúan como icono metafórico de la realidad a la que hacen referencia. En la ficción fantástica o el cuento maravilloso propiamente dichos, en cambio, aun cuando toda ficción literaria constituya una ficción evidente, el lector debe aceptar como reales los acontecimientos (dentro del pacto narrativo entre autor y lector). Naturalmente toda ficción literaria puede ser leída como alegoría. Toda ficción admite los dos tipos de lectura, pero cada obra se inclina por una de las dos vertientes.

Hay en Darío un gusto evidente por lo maravilloso en sus cuentos azules, que corresponden a las reelaboraciones literarias de los cuentos maravillosos, materia que, a través de las recreaciones de autores como Perrault o Madame D'Aulnoy (que escribió un cuento titulado El pájaro azul), fue explotada por 
el simbolismo y que enlaza con el vago medievalismo que forma parte de la imaginería de Darío ${ }^{37}$.

El rubí nos sitúa desde el primer momento en un universo maravilloso donde los gnomos coexisten con la química moderna. No cumple, pues, con las exigencias de verosimilitud del tipo de relato al que se refiere Todorov en su estudio sobre la literatura fantástica, como sí ocurría, en cambio, en La ninfa. Pero tampoco se trata de lo maravilloso popular o exótico, pues en El rubí existe un conflicto con respecto a la realidad, conflicto que simboliza en definitiva la propia creación artística y la exclusión del artista en el mundo actual. En este sentido el texto es definido perfectamente por Dario con el término fantasía.

La presencia de lo mítico y de la mitología en los cuentos de $A z u l .$. (y en el resto de la obra de Darío) se produce, por consiguiente, en distintos niveles. En algunos casos la mitología se utiliza explícitamente dentro de la anécdota del relato, como ocurre en El sátiro sordo, y el universo de la ficción coincide con el mundo especial de la mitología ${ }^{38}$. O bien, como en La ninfa, constituye un universo alternativo. En ambos casos la mitología corresponde a la percepción especial del artista y su capacidad imaginativa. De modo similar se utilizan otras mitologías y universos literarios. En otros casos podemos hablar de mitología subyacente; los relatos responden a modelos arquetípicos, que a su vez coinciden con motivos de los mitos clásicos. Obras posteriores, como el Coloquio de los centauros, suponen una profundización del mito en lo arquetípico. Existen además elementos en la obra de Darío que responden a motivos de la ficción figurativa, como el de la metamorfosis en El rubí, que corresponde al tema de la metamorfosis de la rosa. En la poesía tradicional dicha ficción, a pesar de conservar su raíz mitológica, tenía ante todo carácter figurativo. En Darío, en cambio, se integra en la fantasía y contribuye a esa concentración que distingue al cuento del relato largo y que lo aproxima, como tantas veces se ha señalado, a la poesía ${ }^{39}$.

37 Cf. sobre el motivo del azul en la obra de Darío R. Sulva CASTRO, "El ciclo de "lo azul" en Rubén Darío» (1967), Atenea, 415-416, pp. 233-260.

${ }^{38}$ La presencia del mundo clásico en general en la obra de Darío ha sido estudiada por DoLORES ACKEL FIORE (1963), Rubén Dario in Search of Inspiration (Greco-Roman Mythology in his Stories and Poetry), Las Americas Publishing.

${ }^{34}$ Cf. sobre este aspecto del cuento M. Baquero Goyanfs (1988), "Qué es el cuento", en Qué es la novela; Qué es el cuento, Murcia. 